\title{
Incidence and Predisposing Factors of Vancomycin-Induced Nephrotoxicity in Children
}

\author{
Ahmed R. Ragab • Maha K. Al-Mazroua • \\ Mona A. Al-Harony
}

To view enhanced content go to www.infectiousdiseases-open.com

Received: February 2, 2013 / Published online: March 26, 2013

(C) The Author(s) 2013. This article is published with open access at Springerlink.com

\section{ABSTRACT}

Introduction: To investigate the pattern of vancomycin-associated nephrotoxicity in children and to examine potential predisposing factors for nephrotoxicity, including average serum trough concentrations $\geq 10 \mu \mathrm{g} / \mathrm{mL}$.

Methods: Patients $\geq 1$ week old to $\leq 15$ years with normal baseline serum creatinine values who received vancomycin for $\geq 48 \mathrm{~h}$ between October 2010 and September 2012 were retrospectively evaluated. Nephrotoxicity was defined as a serum creatinine increase of $\geq 0.5 \mathrm{mg} / \mathrm{dL}$ or $\geq 50 \%$ baseline increase over

\section{A. R. Ragab ( $₫)$ · M. A. Al-Harony}

Department of Forensic Medicine and Clinical

Toxicology, Faculty of Medicine, Mansoura

University, Mansoura, Daqahlia, Egypt

e-mail: ahmedrefat1973@yahoo.com

A. R. Ragab · M. K. Al-Mazroua

Dammam Regional Poison Control Center, Almazare'a Street, Dammam, P.O.Box 6712, Kingdom of Saudi Arabia

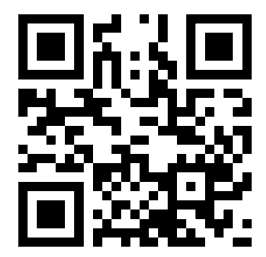

Enhanced content for this article is available on the journal web site: www.infectiousdiseases-open.com
2 days. Patients with average serum trough concentrations $\geq 10 \mu \mathrm{g} / \mathrm{mL}$ were compared with a lower trough group.

Results: Renal toxicity occurred in 72 (27.2\%) of the 265 studied pediatric cases. High trough vancomycin levels $\geq 10 \mu \mathrm{g} / \mathrm{mL}$ were presented in 59 pediatric patients suffering from nephrotoxicity. Using multiple regression analysis, cases admitted to the intensive care unit (ICU) and to whom aminoglycoside medication was administered concurrently with vancomycin medication showed a significant high renal toxicity incidence [odds ratio (OR) 2.91; 95\% confidence interval (CI) 1.70, 8.61; $P$ value $<0.03)]$ and (OR 9.11; 95\% CI $4.11,24.13 ; P<0.05)$, respectively.

Conclusion: Renal function tests and continuous monitoring of vancomycin trough levels for children receiving vancomycin therapy, especially admitted to the ICU and given other aminoglycoside medications, are essential.

Keywords: Methicillin-resistant Staphylococcus aureus infection; Pediatric toxicity; Renal toxicity; Vancomycin nephrotoxicity; Vancomycin therapy; Vancomycin trough level 


\section{INTRODUCTION}

Vancomycin is a bactericidal glycopeptide antibiotic widely used in children for treating methicillin-resistant Staphylococcus aureus (MRSA) infections [1]. In fact, vancomycin trough serum concentrations between 10 and $15 \mu \mathrm{g} / \mathrm{mL}$ have been recommended for serious infections caused by MRSA (including endocarditis, osteomyelitis, meningitis, and pneumonia) [2, 3]. Although this consensus statement excluded recommendations for children, aggressive vancomycin dosing regimens are nonetheless being used with pediatric patients. This dosing may increase the incidence of nephrotoxicity in children.

Vancomycin-associated renal toxicity has been a point of controversy since 1958, when Geraci et al. [4] published the first case series linking to nephrotoxic effects of vancomycin. Since then, several studies have reported an association between vancomycin serum trough concentrations and renal toxicity [5-7].

Although vancomycin has been associated with nephrotoxicity, causality has not been firmly established. Data in adult patients indicate that higher vancomycin doses (or higher serum trough concentrations) are associated with increased nephrotoxicity [8-10]. Nephrotoxicity data associated with higher vancomycin trough attainment through aggressive dosing in the pediatric population are lacking, although nephrotoxicity incidence rates might be higher with increased troughs, as evident in adults.

However, the definition of renal toxicity, as well as the patient population and disease severity, has varied among these studies. Therefore, the authors performed a retrospective, observational clinical study with the main goal of determining the overall incidence rate and predisposing factors associated with development of nephrotoxicity in children receiving vancomycin, including those achieving high average vancomycin serum trough concentrations of $\geq 10 \mu \mathrm{g} / \mathrm{mL}$.

\section{METHODS}

\section{Study Setting}

This study was conducted at Dammam Maternal and Child Hospital (DMCH), a community-based, secondary care hospital. All pediatric patients receiving vancomycin are routinely monitored according to guidelines by toxicologists who perform pharmacokinetic analyses to assess toxicity and goal trough attainment. All Dammam Poison Control Center (DPCC) clinical toxicologists are trained, and have undergone internal competency training and testing in making pharmacokinetic calculations both by manual calculation and with the use of an institutionbased computer kinetic program. Steady-state serum trough concentrations are generally obtained; baseline and periodic serum creatinine (SCr) values are monitored in all patients.

\section{Inclusion and Exclusion Criteria}

In the present retrospective study, eligible pediatric patients were $\geq 1$ week old (and not born prematurely before 37 weeks gestational age) to $\leq 15$ years of age; had received vancomycin for at least $48 \mathrm{~h}$ between October 2010 and September 2012, and had normal baseline SCr values (defined as $\leq 0.6 \mathrm{mg} / \mathrm{dL}$ for patients $\leq 1 \mathrm{month}$ old and $\leq 0.9 \mathrm{mg} / \mathrm{dL}$ for those $>1$ month old). The definition of normal renal function was applied to the start of vancomycin therapy. Patients were required to 
have had one or more serum vancomycin concentrations and repeat SCr values. Premature neonates and infants cared for in the neonatal intensive care unit (ICU) were excluded because DMCH used a separate dosing guideline, and the low muscle mass of these infants may impair prediction of renal impairment.

\section{Study Design}

A retrospective cohort design was employed to assess the effect of vancomycin serum trough concentrations on the occurrence of renal toxicity. The study protocol was approved by the DPCC review board, with complete confidentiality of patient information records as maintained by keeping patients names anonymous. This article does not contain any studies with human or animal subjects performed by any of the authors. Patients were identified using the toxicology clinical monitoring database Online Analytical Toxicology Request and Result (OTARR). Only the first course of vancomycin was evaluated if multiple courses were given during the study period. Electronic medical records and pharmacokinetic monitoring forms were reviewed. Pertinent data, including demographics, laboratory details, vancomycin dosing, and pharmacokinetics, were collected on standardized forms. Concomitant use of nephrotoxins, such as aminoglycosides, cyclosporine, tacrolimus, furosemide, or amphotericin, was recorded. The $\mathrm{DMCH}$ protocol for intravenous administration of vancomycin requires measurement of steadystate trough concentrations, with a target of 5-10 $\mu \mathrm{g} / \mathrm{mL}$ for both serious and non-serious infectious status.

A MEDLINE search was performed using the keywords "vancomycin," "renal toxicity," "renal failure," "creatinine," and "creatinine clearance." Based on this literature review, renal toxicity was defined as either a $\geq 0.5 \mathrm{mg} /$ $\mathrm{dL}$ increase from baseline in SCr or a $\geq 50 \%$ increase from baseline in $\mathrm{SCr}$ based on serial $\mathrm{SCr}$ measurements over 2 days [8,9]. Baseline SCr and age- and sex-adjusted creatinine clearance calculations were made before administration of vancomycin in all patients, using the following formula [10]: Estimated creatinine clearance $=(140-$ age $) \quad($ weight in $\mathrm{kg}) /$ $(72 \times$ serum creatinine $) \times 0.085$ (women only) .

\section{Grouping of the Studied Patients}

An average vancomycin trough level was calculated using all measured serum concentration results throughout therapy. Baseline vancomycin clearance $(\mathrm{L} / \mathrm{h})$ was obtained from pharmacokinetic values from the first steady-state vancomycin concentration, using the population volume of distribution. High trough therapy was defined as an average serum trough concentration of $\geq 10 \mu \mathrm{g} / \mathrm{mL}$ and low trough therapy as an average serum trough concentration of $<10 \mu \mathrm{g} / \mathrm{mL}$ for all concentrations throughout therapy.

\section{Statistical Analysis}

All comparisons were unpaired, and all tests of significance were two-tailed. Continuous variables were compared using the Student $t$ test for normally distributed variables, and the Mann-Whitney $U$ test for non-normally distributed variables. The Chi-square test was used to compare categoric variables. The primary data analysis compared patients who met the study definition for renal toxicity with those who did not. Values were expressed as mean $( \pm \mathrm{SD})$ for continuous variables and as a percentage of the group from which they were 
derived for categoric variables. $P$ value was twotailed, and $P \leq 0.05$ was considered statistically significant. The authors performed multiple logistic regression analyses using SPSS $^{\circledR}$ for Windows version 19.0 (SPSS Inc., Chicago, IL, USA). Multivariate analysis was performed using models that were judged a priori to be clinically sound [11]; this was prospectively determined to be necessary to avoid producing spuriously significant results with multiple comparisons. All potential risk factors that were significant at the 0.2 level in univariate analyses were entered into the model. A stepwise approach was used to enter new terms into the logistic regression model, in which renal toxicity was the dependent outcome variable and 0.05 was set as the limit for the acceptance or removal of new terms.

\section{RESULTS}

Table 1 shows the demographic and clinical data characteristics of the studied pediatric cases receiving vancomycin therapy. The total number of cases was 265, of which 130 were male. Gender factor had no clinically significant difference between high and low trough vancomycin levels. Some parameters in the studied table showed a significant difference when comparing a low vancomycin trough level $<10 \mu \mathrm{g} / \mathrm{mL}$ with a high vancomycin level $\geq 10 \mu \mathrm{g} / \mathrm{mL}$; these were mean age $(P>0.030)$, meningitis $(P>0.026)$, dermal infectious status $(P>0.031)$, mean initial $(P=0.001)$ and overall $(P=0.032)$ vancomycin dosage, and frequency of ICU admitted cases $(P=0.041)$. Other parameters showed a non-significant difference when comparing a low vancomycin trough level $<10 \mu \mathrm{g} / \mathrm{mL}$ with a high vancomycin level $\geq 10 \mu \mathrm{g} / \mathrm{mL}$; these were bacteremia, pneumonia, myocarditis, arthritis, endocarditis, malignancy, former prematurity, congenital heart disease, respiratory disease, and respiratory distress syndrome.

Table 2 presents the variable parameters related to the renal profile in children receiving vancomycin therapy. Parameters that showed a significant difference were the frequency of nephrotoxicity $(P=0.0001)$, mean time of occurrence of nephrotoxicity $(P=0.042)$, mean vancomycin dose at toxicity time $(P=0.031)$, mean peak $(P=0.033)$ and end $(P=0.024)$ of therapy SCr levels, frequency of very high increase SCr level above baseline $(>0.5 \mathrm{mg} / \mathrm{dL}) \quad(P=0.001), \quad$ and mean vancomycin clearance rate at peak $(P=0.029)$ and end $(P=0.043)$ of vancomycin medication course. Renal toxicity occurred in $72(27.2 \%)$ of the 265 studied pediatric cases.

The effect of the mean vancomycin trough level, duration of vancomycin therapy, mean SCr level, mean vancomycin clearance, and concomitant nephrotoxin medication are clearly shown in Table 3 . The percentage of nephrotoxicity occurrence clearly shows a significant difference in the previously mentioned predisposing factors (mean vancomycin trough level, $P=0.002$; duration of vancomycin therapy, $P=0.041$; mean $\mathrm{SCr}$ level, $P=0.000$; mean vancomycin clearance change, $P=0.029$; and concomitant amino glycosides, $P=0.001$ ).

Using multiple regression analysis, cases admitted to the ICU and to whom aminoglycoside medication was administered concurrently with vancomycin medication showed a significant high renal toxicity incidence [odds ratio (OR) 2.91; 95\% confidence interval (CI) 1.70, 8.61; $P$ value $<0.03$ )] and (OR 9.11; 95\% CI 4.11, 24.13; $P<0.05)$, respectively.

Figure 1 shows the percentage of renal toxicity according to the vancomycin trough level. The highest percentage was found in the 
Table 1 Demographic, baseline, and patients characteristic of children receiving vancomycin (total $n=265$ )

\begin{tabular}{|c|c|c|c|}
\hline Characteristics & Low trough $(n=166)$ & High trough $(n=99)$ & $P$ value \\
\hline Male, $n(\%)$ & $82(49.4)$ & $48(48.5)$ & 0.263 \\
\hline Mean age, years $( \pm S D)$ & $2.1 \pm 1.9$ & $1.7 \pm 1.3$ & $0.030^{*}$ \\
\hline Mean weight, $\mathrm{kg}( \pm \mathrm{SD})$ & $7.37 \pm 11.7$ & $6.1 \pm 7.4$ & 0.188 \\
\hline \multicolumn{4}{|l|}{ Infection type, $n(\%)$} \\
\hline Bacteremia & $72(43.4)$ & $47(47.5)$ & 0.35 \\
\hline Pneumonia & $66(39.8)$ & $28(28.2)$ & 0.833 \\
\hline Meningitis & $7(4.2)$ & $13(13.1)$ & $0.026^{*}$ \\
\hline Dermal infection & $6(3.6)$ & $12(12.1)$ & $0.031^{*}$ \\
\hline Myocarditis & $5(3.0)$ & $4(4.0)$ & 0.435 \\
\hline Arthritis & $6(3.6)$ & $7(7.1)$ & 0.712 \\
\hline Endocarditis & $4(2.4)$ & $2(2.0)$ & 0.551 \\
\hline Culture positive for MRSA, $n(\%)$ & $31(18.7)$ & $11(11.1)$ & 0.327 \\
\hline \multicolumn{4}{|l|}{ Chronic illness, $n$ (\%) } \\
\hline Malignancy & $5(3.0)$ & $11(11.1)$ & 0.672 \\
\hline Former prematurity & $21(12.7)$ & $16(16.2)$ & 0.183 \\
\hline Congenital heart disease & $11(6.6)$ & $13(13.1)$ & 0.417 \\
\hline Respiratory disease & $12(7.2)$ & $7(7.1)$ & 0.123 \\
\hline Respiratory distress syndrome & $11(6.6)$ & $2(2.0)$ & 0.327 \\
\hline \multicolumn{4}{|l|}{ Concomitant nephrotoxin, $n$ (\%) } \\
\hline Aminoglycosides & $52(31.3)$ & $12(12.1)$ & 0.051 \\
\hline Cyclosporine & $6(3.6)$ & $3(3.0)$ & 0.341 \\
\hline Tacrolimus & $3(1.8)$ & $1(1.0)$ & 0.360 \\
\hline Non-steroidal anti-inflammatory & $17(10.2)$ & $10(10.1)$ & 0.172 \\
\hline Amphotericin & $3(1.8)$ & $3(3.0)$ & 0.562 \\
\hline Loop diuretic "furosemide" & $22(13.3)$ & $18(18.2)$ & 0.342 \\
\hline \multicolumn{4}{|l|}{ Initial vancomycin dose, $\mathrm{mg} / \mathrm{kg} /$ day } \\
\hline Mean $( \pm S D)$ & $36.1(24.6)$ & $47.4(15.5)$ & $0.001^{*}$ \\
\hline \multicolumn{4}{|c|}{ Overall vancomycin dose therapy, $\mathrm{mg} / \mathrm{kg} /$ day } \\
\hline Mean $( \pm S D)$ & $32.2 \pm 22.3$ & $41.2 \pm 17.3$ & $0.032^{*}$ \\
\hline \multicolumn{4}{|l|}{ Duration of vancomycin therapy, days } \\
\hline Mean $( \pm S D)$ & $12.1 \pm 8.4$ & $14.4 \pm 5.1$ & 0.120 \\
\hline \multicolumn{4}{|l|}{ Duration of hospital stay, days } \\
\hline Mean $( \pm S D)$ & $17.2 \pm 14.1$ & $22.4 \pm 15.1$ & 0.471 \\
\hline
\end{tabular}


Table 1 continued

\begin{tabular}{llll}
\hline Characteristics & Low trough $(\boldsymbol{n}=166)$ & High trough $(\boldsymbol{n}=99)$ & $\boldsymbol{P}$ value \\
\hline Range & $6-24$ & $9-41$ & \\
ICU admission & & $37(37.4)$ & $0.041^{*}$ \\
$n(\%)$ & $38(22.9)$ & $9.3(4.1)$ & 0.371 \\
Duration stay, days $( \pm S D)$ & $15.3(12.1)$ &
\end{tabular}

$I C U$ intensive care unit, MRSA methicillin-resistant Staphylococcus aureus, SD standard deviation

${ }^{*} P$ value significant $\leq 0.05$

Table 2 Renal kinetics profile in children receiving vancomycin

\begin{tabular}{llll}
\hline Parameters & Low trough $(\boldsymbol{n}=\mathbf{1 6 6})$ & High trough $(\boldsymbol{n}=\mathbf{9 9})$ & $\boldsymbol{P}$ value \\
\hline Nephrotoxicity during therapy, $n(\%)$ & $13(7.8)$ & $59(59.6)$ & $0.0001^{*}$ \\
Time of nephrotoxicity, days mean $( \pm \mathrm{SD})$ & $6.3(3.7)$ & $3.2(1.4)$ & $0.042^{*}$ \\
Vancomycin dose at toxicity time, mg/kg mean $( \pm \mathrm{SD})$ & $33.6(10.1)$ & $46.2(13.7)$ & $0.031^{*}$ \\
Serum creatinine level, mg/dL mean $( \pm \mathrm{SD})$ & & & \\
Baseline & $0.57(0.2)$ & $0.67(0.51)$ & 0.325 \\
Peak & $0.68(0.3)$ & $0.81(0.34)$ & $0.033^{*}$ \\
End of therapy & $0.54(0.7)$ & $0.62(0.6)$ & $0.024^{*}$ \\
Serum creatinine $\geq 0.5 \mathrm{mg} / \mathrm{dL}$ above baseline, $n(\%)$ & $4(2.4)$ & $19(19.2)$ & $0.001^{*}$ \\
Vancomycin clearance, $\mathrm{L} / \mathrm{h}$ mean $( \pm \mathrm{SD})$ & & & 0.231 \\
Baseline & $2.2(2.1)$ & $1.9(1.1)$ & $0.029^{*}$ \\
Peak & $1.85(1.7)$ & $1.53(0.7)$ & $0.043^{*}$ \\
End of therapy & $2.1(1.9)$ & $1.81(1.3)$ & \\
Total renal toxicity incidence in 265 & $72(27.2 \%)$ & & \\
studied pediatric cases, $n(\%)$ & & & \\
\hline
\end{tabular}

${ }^{*} P$ value significant $\leq 0.05$

vancomycin trough level therapy $>15 \mu \mathrm{g} / \mathrm{mL}$ (87.5\%), with a significant difference when compared with low vancomycin trough level $<10 \mu \mathrm{g} / \mathrm{mL}(P<0.001)$.

\section{DISCUSSION}

MRSA infection in children is treated mainly by vancomycin, a bactericidal glycopeptide antibiotic. There are two medical protocols regarding the use of vancomycin therapy in the treatment of serious infection caused by MRSA. One of these suggests keeping the trough serum vancomycin concentration at 5-10 $\mu \mathrm{g}$ / $\mathrm{mL}$, as with other non-serious infections, and the other advises increasing the vancomycin level to between 10 and $15 \mu \mathrm{g} / \mathrm{mL}$. The protocol applied in $\mathrm{DMCH}$ is the first vancomycin 
Table 3 Vancomycin therapy and changes in renal functions

\begin{tabular}{|c|c|c|c|}
\hline Parameters & $\begin{array}{l}\text { Renal toxicity absent } \\
(n=94)\end{array}$ & $\begin{array}{l}\text { Renal toxicity present } \\
(n=72)\end{array}$ & $P$ value \\
\hline \multicolumn{4}{|l|}{ Vancomycin trough, $\mu \mathrm{g} / \mathrm{mL}$} \\
\hline Mean $( \pm S D)$ & $8.4(3.1)$ & $17.1(4.7)$ & $0.002^{*}$ \\
\hline Frequency, mean (range) & $5.3(3-7)$ & $7.4(4-13)$ & 0.536 \\
\hline $\begin{array}{l}\text { Duration of vancomycin therapy }>14 \text { days, } \\
n(\%)\end{array}$ & $13(13.8)$ & $31(43.1)$ & $0.041^{*}$ \\
\hline \multicolumn{4}{|l|}{ Serum creatinine level, mg/dL mean $( \pm S D)$} \\
\hline Maximum & $0.56(0.4)$ & $0.91(0.37)$ & $0.000^{*}$ \\
\hline Change & $0.12(0.2)$ & $0.83(0.22)$ & $0.000^{*}$ \\
\hline \multicolumn{4}{|l|}{ Vancomycin clearance, $\mathrm{L} / \mathrm{h}$ mean $( \pm S D)$} \\
\hline Minimum & $2.4(2.2)$ & $1.7(0.9)$ & 0.231 \\
\hline Change & $0.2(0.03)$ & $1.1(0.01)$ & $0.029^{*}$ \\
\hline \multicolumn{4}{|l|}{ Concomitant nephrotoxins, $n(\%)$} \\
\hline Aminoglycosides & $26(27.7)$ & $38(52.8)$ & $0.001^{*}$ \\
\hline Cyclosporine & $3(3.2)$ & $6(8.3)$ & 0.728 \\
\hline Tacrolimus & $2(2.1)$ & $2(2.8)$ & 0.921 \\
\hline Non-steroidal anti-inflammatory & $6(6.4)$ & $11(15.3)$ & 0.414 \\
\hline Amphotericin & $1(1.1)$ & $4(5.6)$ & 0.827 \\
\hline Loop diuretic "furosemide" & $17(18.1)$ & $23(31.9)$ & 0.071 \\
\hline
\end{tabular}

${ }^{*} P$ value significant $\leq 0.05$

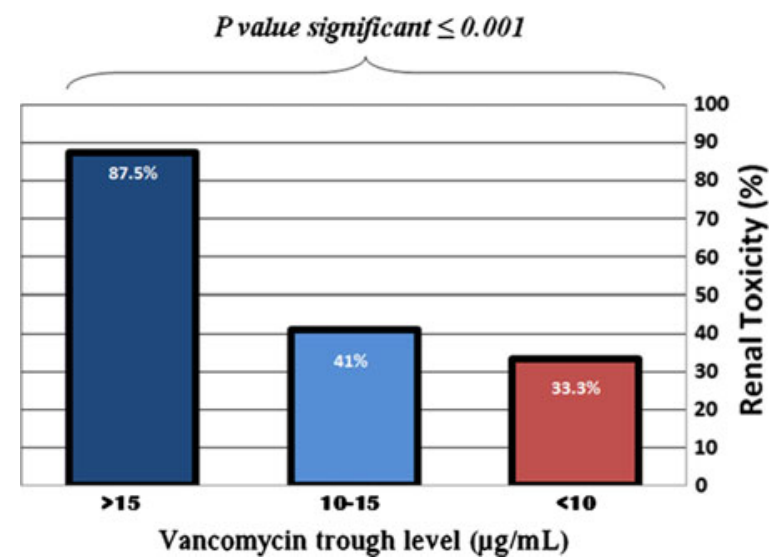

Fig. 1 Incidence of renal toxicity stratified by vancomycin steady-serum trough concentration

protocol that keeps the trough level between 5-10 $\mu \mathrm{g} / \mathrm{mL}$.
The present study was performed to clarify the vague relationships among different variables in the studied pediatric cases, such as age, weight, indication of vancomycin therapy, admission status, duration of therapy, concomitant nephrotoxin usage with vancomycin medication, vancomycin dosage and trough level, and renal functions status in studied children. The definition of renal failure terminology applied in the current study followed that in many documented references [8-10] as previously mentioned.

In the studied literature, the incidence of renal failure in adult patients treated with vancomycin ranged from $12 \%$ to $42 \%$, and 
this percentage was markedly elevated to reach its maximum percentage (42\%) when other aminoglycoside medications were used with vancomycin therapy $[12,13]$.

In the present study, $27.2 \%$ of the studied children suffered from renal toxicity during vancomycin therapy, and the incidence of renal toxicity increased when the vancomycin trough level became $>10-15 \mu \mathrm{g} / \mathrm{mL}(41 \%)$ and reached its peak in $87.5 \%$ of cases with serum trough vancomycin levels of $>15 \mu \mathrm{g} / \mathrm{mL}$. In accordance with the presented figures, several adult and pediatric studies documented the previously noted information $[8,14]$.

In the present study, other factors have been reported that can affect the incidence of occurrence of renal toxicity beside the vancomycin serum level. These include duration of vancomycin therapy, concomitant usage of aminoglycosides, ICU admission status, presence of bacterial meningitis, presence of bacterial dermal infection, age, and weight of the studied pediatric cases.

In the present study of 72 cases suffering from renal toxicity, there were 38 pediatric cases who were given aminoglycosides as well as vancomycin therapy. About one-third (37.4\%) of the studied pediatric cases with high vancomycin trough levels were admitted to the ICU. The studied pediatric cases with high vancomycin trough levels of $\geq 10 \mu \mathrm{g} / \mathrm{dL}$ were associated with high mean overall vancomycin dose $(41.2 \mathrm{mg} / \mathrm{kg} / \mathrm{d})$ when compared with low trough level $<10 \mu \mathrm{g} / \mathrm{mL}(32.2 \mathrm{mg} / \mathrm{kg} / \mathrm{d})$, with a significant difference $(P=0.032)$. In accordance with the present results, one study of adult cases found a significant nephrotoxicity percentage among patients receiving a high dose of vancomycin therapy and who were admitted to the ICU [15].

In the present study, most of the pediatric cases suffering from nephrotoxicity induced by vancomycin therapy were associated with a significant increasing SCr level that returned to the average baseline concentration at the end of therapy or hospital discharge. In accordance with the present findings, one study by Jeffries et al. [9] stated that $72 \%$ of the studied cases of patients suffering from vancomycin-induced nephrotoxicity had a high creatinine level that returned to baseline at the time of hospital discharge.

Regarding the time of occurrence of vancomycin-induced renal toxicity, several studies reported that the onset of renal toxicity mainly occurs after a lapse of 1-3 weeks from the onset of vancomycin therapy in adult patients $[2,9,10]$. In the present study, the time of occurrence of renal toxicity occurred in the first week for renal toxicity associated with both high and low trough vancomycin levels.

The duration of vancomycin therapy plays an important role in the induction of vancomycin-induced nephrotoxicity. Hidayat et al. [2] stated that increasing the duration of vancomycin therapy was associated with an increase in the incidence of occurrence of renal toxicity, and approximately $30 \%$ of the studied cases associated with nephrotoxicity were patients receiving vancomycin therapy for more than 14 days, while it was only $6.3 \%$ in adult patients receiving vancomycin therapy for less than 1 week.

\section{CONCLUSION}

The present work discussed the impact of vancomycin therapy in the renal function of the pediatric population. The result of this study showed that vancomycin-induced renal toxicity existed in $27.2 \%$ of the studied cases, and the incidence of renal toxicity was significantly increased with high trough vancomycin levels of 
$\geq 10 \mu \mathrm{g} / \mathrm{mL}$. Admission to the ICU, prolongation of vancomycin therapy, and concurrent administration of other aminoglycoside medications during vancomycin therapy increased the incidence of renal toxicity in pediatric studied cases. In conclusion, renal functions tests and continuous monitoring of vancomycin trough levels for children receiving vancomycin therapy, especially admitted to the ICU and given other aminoglycoside medications, are essential.

\section{ACKNOWLEDGMENTS}

No funding or sponsorship was received for this study or publication of this article. Dr. Ahmed Refat Ragab is the guarantor for this article, and takes responsibility for the integrity of the work as a whole.

Conflict of interest. Ahmed R. Ragab, Maha K. Al-Mazroua, and Mona A. Al-Harony declare no conflict of interest.

Compliance with Ethics Guidelines. This article does not contain any studies with human or animal subjects performed by any of the authors.

Open Access. This article is distributed under the terms of the Creative Commons Attribution Noncommercial License which permits any noncommercial use, distribution, and reproduction in any medium, provided the original author(s) and the source are credited.

\section{REFERENCES}

1. Gerber JS, Coffin SE, Smathers SA, Zaoutis TE. Trends in the incidence of methicillin-resistant Staphylococcus aureus infection in children's hospitals in the United States. Clin Infect Dis. 2009;49:65-71.

2. Hidayat LK, Hsu DI, Quist R, Shriner KA, WongBeringer A. High dose vancomycin therapy for methicillin-resistant Staphylococcus aureus infections: efficacy and toxicity. Arch Intern Med. 2006; 166:2138-44.

3. Ryback M, Lomaestro B, Rotschafer JC, et al. Therapeutic monitoring of vancomycin in adult patients: a consensus review of the American Society of Health-System Pharmacists, the Infectious Diseases Society of American, and the Society of Infectious Diseases Pharmacists. Am J Health Syst Pharm. 2009;66:82-98.

4. Geraci JE, Heilman FR, Nichols DR, Wellman WE. Antibiotic therapy of bacterial endocarditis. VII. Vancomycin for acute micrococcal endocarditis: preliminary report. Proc Staff Meet Mayo Clin. 1958;33:172-81.

5. Kralovicova K, Spanik S, Halko J. Do vancomycin serum levels predict failures of vancomycin therapy or nephrotoxicity in cancer patients? J Chemother. 1997;9:420-6.

6. Zimmermann AE, Katona BG, Plaisance KI. Association of vancomycin serum concentrations with outcomes in patients with gram-positive bacteremia. Pharmacotherapy. 1995;15:85-91.

7. Elting LS, Rubenstein EB, Kurtin D, et al. Mississippi mud in the 1990s: risks and outcomes of vancomycin-associated toxicity in general oncology practice. Cancer. 1998;83:2597-607.

8. Hermsen ED, Hanson M, Sankaranarayanan J, Stoner JA, Florescu MC, Rupp ME. Clinical outcomes and nephrotoxicity associated with vancomycin trough concentrations during treatment of deep-seated infections. Expert Opin Drug Saf. 2010;9:9-14.

9. Jeffries MN, Isakow W, Doherty JA, Micek ST, Kollef $\mathrm{MH}$. A retrospective analysis of possible renal toxicity associated with vancomycin in patients with health care-associated methicillin-resistant Staphylococcus aureus pneumonia. Clin Ther. 2007;29:1107-15.

10. Lodise TP, Lomaestro B, Graves J, Drusano GL. Larger vancomycin doses (at least 4 grams per day) are associated with an increased incidence of nephrotoxicity. Antimicrob Agents Chemother. 2008;52:1330-6.

11. Concato J, Feinstein AR, Holford TR. The risk of determining risk with multivariable models. Ann Intern Med. 1993;118:201-10. 
12. American Thoracic Society. Infectious Diseases Society of America. Guidelines for the management of adults with hospital-acquired, ventilatorassociated, and healthcare-associated pneumonia. Am J Respir Crit Care Med. 2005;171:388-416.

13. Lodise TP, Patel N, Lomaestro BM, Rodvold KA, Drusano GL. Relationship between initial vancomycin concentration-time profile and nephrotoxicity among hospitalized patients. Clin Infect Dis. 2009;49:507-14.
14. Rybak MJ, Albrecht LM, Boike SC, Chandrasekar $\mathrm{PH}$. Nephrotoxicity of vancomycin, alone and with aminoglycoside. J Antimicrob Chemother. 1990;25:679-87.

15. Kollef MH, Rello J, Cammarata SK. Clinical cure and survival in Gram-positive ventilator-associated pneumonia: retrospective analysis of two doubleblind studies comparing linezolid with vancomycin. Intensive Care Med. 2004;30:388-94. 